\title{
Effect of Granulocyte Colony-stimulating Factor and Erythropoietin on Patients with Acute-on-chronic Liver Failure
}

\author{
Md Nazmul Haque ${ }^{1}$, Mamun Al-Mahtab², Dulal C Das ${ }^{3}$, Noor-E-Alam Sheikh Mohammad ${ }^{4}$, Ayub A Mamun $^{5}$, \\ Md Sakirul I Khan ${ }^{6}$, Sheikh MF Akbar ${ }^{7}$, Salimur Rahman ${ }^{8}$
}

\begin{abstract}
Introduction: Patients with acute-on-chronic liver failure (ACLF) have low survival without liver transplantation. Granulocyte colony-stimulating factor (G-CSF) improves survival in ACLF and erythropoietin (EPO) promotes hepatic regeneration in animal studies. The aim of this study is to determine whether coadministration of G-CSF and EPO improves the outcome in ACLF.

Methods: The study was conducted in the Department of Hepatology, Bangabandhu Sheikh Mujib Medical University, Dhaka. Consecutive patients with ACLF were randomly assigned into group A and group B. Group A patients received subcutaneous G-CSF (5 mcg/kg/d) for 6 days and subcutaneous EPO ( $40 \mathrm{mcg} / \mathrm{wk}$ ) for 4 weeks and group B patients received only standard medical care (control group). All patients were followed up for 3 months. The primary end point was to see survival at 3 months.

Results: Patients had comparable baseline characteristics; hepatitis B virus infection was the commonest etiology of ACLF as both acute and chronic events. A higher proportion of patients were male in both groups. The survival was higher in group A than in group B at the end of 3 months ( $36.4 \%$ vs $29.4 \% ; p=0.457$ ), but this was not statistically significant. Regarding complications, hepatorenal syndrome was higher in group B than in group A (36.7\% vs 41.7\%). In both the groups, Child-Turcotte-Pugh score and model for end-stage liver disease scores were similar before treatment and improved during follow-up.

Conclusion: This is one of the early human studies that demonstrate potential hepatic regeneration using EPO in ACLF patients. Further study with a larger cohort will be needed to reproduce the results of the present work.

Keywords: Acute-on-chronic liver failure, Erythropoietin, Granulocyte colony-stimulating factor.

Euroasian Journal of Hepato-Gastroenterology (2020): 10.5005/jp-journals-10018-1330
\end{abstract}

\section{INTRODUCTION}

Acute-on-chronic liver failure (ACLF) is the outcome of acute insult of the liver on the background of an underlying compensated chronic liver disease. The Asian Pacific Association for the Study of the Liver (APASL) defines ACLF as an acute hepatic insult that is characterized by jaundice (serum bilirubin level $>5.0 \mathrm{mg} / \mathrm{dL}$ ) and coagulopathy (international normalized ratio $\geq 1.5$ ). The condition is complicated by ascites and/or encephalopathy within 4 weeks. The underlying chronic liver disease may or may not have been diagnosed previously. ${ }^{1}$ ACLF is characterized by high mortality that results from multiorgan failure. ${ }^{2} \mathrm{~A}$ systemic meta-analysis reported mortality rate as $51 \%{ }^{3}$ The mortality may be $65 \%$ at 3 months. ${ }^{4}$

The curative treatment for ACLF is liver transplantation. However, there are several hurdles like shortage of donors, high cost, and lack of expertise that limit its use in ACLF. New options for treatment of ACLF therefore need to be evaluated. It is established that blood-derived stem cells can differentiate into multiple cell lines. Therefore, when tissue-intrinsic stem cells are overwhelmed, these blood-derived stem cells may be employed for tissue repair. ${ }^{5}$

There is evidence in the literature that hepatic regeneration may be stimulated by bone marrow-derived stem cells. ${ }^{6}$ Granulocyte colony-stimulating factor (G-CSF) mobilizes CD34+ cells and improves the survival of ACLF patients. ${ }^{7}$ These CD34+ cells increase hepatocyte growth factor inducing the proliferation of hepatic progenitor cells within 7 days in alcoholic steatohepatitis. ${ }^{8}$
${ }^{1}$ Department of Medicine, Pabna Medical College and Hospital, Pabna, Bangladesh

2-5,8 Department of Hepatology, Bangabandhu Sheikh Mujib Medical University, Dhaka, Bangladesh

${ }^{6}$ Department of Anatomy and Embryology, Ehime University Graduate School of Medicine, Ehime, Japan

${ }^{7}$ Department of Gastroenterology and Metabology, Ehime University Graduate School of Medicine, Ehime, Japan

Corresponding Author: Mamun Al-Mahtab, Department of Hepatology, Bangabandhu Sheikh Mujib Medical University, Dhaka, Bangladesh, Phone: +880 1711567275, e-mail: shwapnil@agni.com

How to cite this article: Haque Md N, Al-Mahtab M, Das DC, et al. Effect of Granulocyte Colony-stimulating Factor and Erythropoietin on Patients with Acute-on-chronic Liver Failure. Euroasian J HepatoGastroenterol 2020;10(2):64-67.

Source of support: Nil

Conflict of interest: None

Mookerjee et al. have shown that neutrophil dysfunction in alcoholic hepatitis superimposed on the background of cirrhosis results in sepsis and hepatorenal syndrome (HRS). ${ }^{9} \mathrm{G}-\mathrm{CSF}$ therapy also improves neutrophil function in glycogen storage disease type Ib. ${ }^{10}$

Recombinant human erythropoietin (EPO) results in improved survival of mouse with liver failure induced by D-galactosamine/ 
lipopolysaccharide. ${ }^{11}$ Combination of G-CSF and EPO has shown on the contrary to improve outcomes in decompensated cirrhosis. ${ }^{12}$ Since G-CSF and EPO have different mechanisms and actions as well as different target cells, it has been hypothesized that when used in combination they will potentiate hepatic regeneration and improve survival in ACLF.

\section{Methods}

This study was carried out at the Department of Hepatology at Bangabandhu Sheikh Mujib Medical University, Dhaka. Study participants were briefed about the potential benefits and risks of the use of G-CSF, and patients were randomized into two groups. Half of them (group A) were selected for standard medical care plus G-CSF and EPO, and the other half (group B) were selected for only standard medical care. Patients in group $A$ received subcutaneous G-CSF ( $5 \mu \mathrm{g} / \mathrm{kg} /$ day) for 6 days together with subcutaneous EPO ( $40 \mathrm{mcg} / \mathrm{wk}$ ) for 4 weeks and standard medical care. Patients in both groups received standard medical care including antiviral agents, intravenous antibiotics, supervised diet, lactulose, and close monitoring, as needed. Nasogastric feeding or parenteral nutrition was provided as and when required. Data were collected using a preformed questionnaire. Child-Turcotte-Pugh (CTP) score and model for end-stage liver disease (MELD) score were employed to assess the severity of the liver disease.

Clinical assessment (appetite, sleeping pattern, level of consciousness, bowel habit, color of stool, color of urine, urine output, jaundice, flapping tremor, ascites, etc.) and investigations (complete blood count, alanine transaminase, aspartate transaminase, total bilirubin, prothrombin time (PT), international normalized ratio (INR), serum albumin, serum creatinine, and serum electrolyte) were done at $0,7,15,30$, and 60 days and at the time of deterioration and then at 90 days. Ultrasonogram of whole abdomen was repeated at day 90 to see the presence or absence of ascites. Adverse effect of G-CSF and EPO therapy was closely monitored throughout the study in each patient.

Survival at 90 days and improvement in MELD, MELDNa, CTP scores, and hepatitis B virus (HBV) DNA level were primary and secondary end points, respectively.

Quantitative data were presented as mean \pm standard deviation (SD), and qualitative data were presented in percentage. All data were analyzed by SPSS. Qualitative data were analyzed by chisquare test, and quantitative data were analyzed by Student t-test. Chi-square test was used to check the association between two qualitative variables. Regression analysis was done for confounding variable to explore the effect on mortality. A statistically significant result was considered when $p$-value was less than 0.05 .

Prior to the commencement of this study, the protocol was approved by the institutional review board of Bangabandhu Sheikh Mujib Medical University, Dhaka.

\section{Results}

Median age was $42.64 \pm 10.39$ years in group $A$ and $42.18 \pm 13.06$ years in group $B$. Nineteen patients were male and 3 patients were female among the total 22 patients in group $A$, and 12 patients were male and 5 patients were female among the total 17 patients in group B. Median CTP score was $11.77 \pm 1.11$ in group A and $11.65 \pm 1.36$ in group $B$. The median MELD score was $27.64 \pm 4.60$ in group $A$ and $29.47 \pm 5.53$ in group $B$. The median MELDNa score was $29.73 \pm 4.62$ in group $A$ and $30.76 \pm 5.29$ in group $B$.
Fourteen patients (63.6\%) in group A and 8 (41.1\%) in group $B$ had reactivation of $\mathrm{HBV}$ as the acute event. Seventeen patients (77.3\%) in group A and 9 (52.9\%) in group B had HBV cirrhosis as the underlying chronic liver disease (Table 1).

Mean MELD scores reduced significantly $(p<0.05)$ in both groups compared to the pretreatment state (Table 2). After 90 days, 8 patients (36.4\%) survived in group A and $5(29.4 \%)$ in group $B$. The difference was not statistically significant (Table 3 ).

It was observed that a maximum of 5 patients (35.7\%) died from HRS in group A and 5 (41.7\%) in group B. Three $(21.4 \%)$ patients died from hepatic encephalopathy (HE) in group $A$ and 2 $(16.7 \%)$ in group B. Four (28.6\%) had variceal bleeding as the cause

Table I: Etiology of the acute event and underlying chronic liver disease

\begin{tabular}{lcccc}
\hline & $\begin{array}{c}\text { Group A } \\
(n=22)\end{array}$ & $\begin{array}{c}\text { Group B } \\
(n=17)\end{array}$ \\
\cline { 2 - 5 } Acute event and chronic insult & $n$ & $\%$ & $n$ & $\%$ \\
\hline Acute event & 14 & 63.6 & 8 & 41.1 \\
$\quad$ Reactivation of HBV & 4 & 18.2 & 4 & 23.5 \\
$\quad$ Drug induced & 1 & 4.5 & 3 & 17.6 \\
Hepatitis E virus infection & 3 & 13.6 & 0 & 0 \\
Hepatitis A virus infection & 0 & 0 & 2 & 11.8 \\
$\quad$ Unknown & & & & \\
\hline Underlying chronic liver disease & 17 & 77.3 & 9 & 52.9 \\
$\quad$ HBV cirrhosis & 0 & 0 & 2 & 11.8 \\
$\quad$ Hepatitis C virus cirrhosis & 3 & 13.6 & 1 & 5.9 \\
$\quad$ Chronic hepatitis B & 0 & 0 & 1 & 5.9 \\
$\quad$ Nonalcoholic steatohepatitis & & & & \\
$\quad$ Cirrhosis & 1 & 4.5 & 1 & 5.9 \\
$\quad$ Wilson's disease & 1 & 4.5 & 3 & 17.6 \\
$\quad$ Unknown & & & & \\
\hline
\end{tabular}

Table 2: MELD score at different follow-ups

\begin{tabular}{|c|c|c|c|}
\hline & Group A & Group B & \\
\hline MELD Score & Mean $\pm S D$ & Mean $\pm S D$ & $p$-value \\
\hline $\begin{array}{l}\text { Pretreatment ( } 0 \text { days) } \\
\text { Range (min-max) }\end{array}$ & $\begin{array}{l}(n=22) \\
27.64 \pm 4.6 \\
22-40\end{array}$ & $\begin{array}{l}(n=17) \\
29.47 \pm 5.5 \\
22-40\end{array}$ & ${ }^{\mathrm{a}} 0.266^{\mathrm{ns}}$ \\
\hline $\begin{array}{l}\text { 1st Follow-up (7 days) } \\
\text { Range (min-max) }\end{array}$ & $\begin{array}{l}(n=22) \\
28.45 \pm 7.5 \\
16-47\end{array}$ & $\begin{array}{l}(n=15) \\
27.27 \pm 7.7 \\
15-42\end{array}$ & ${ }^{\mathrm{a}} 0.645^{\mathrm{ns}}$ \\
\hline $\begin{array}{l}\text { 2nd Follow-up ( } 15 \text { days) } \\
\text { Range (min-max) }\end{array}$ & $\begin{array}{l}(n=15) \\
24.73 \pm 4.8 \\
14-34\end{array}$ & $\begin{array}{l}(n=13) \\
26.23 \pm 7.1 \\
11-38\end{array}$ & ${ }^{\mathrm{a}} 0.519^{\mathrm{ns}}$ \\
\hline $\begin{array}{l}\text { 3rd Follow-up (30 days) } \\
\text { Range (min-max) }\end{array}$ & $\begin{array}{l}(n=14) \\
25.45 \pm 6.8 \\
11-39\end{array}$ & $\begin{array}{l}(n=10) \\
27.60 \pm 8.5 \\
16-40\end{array}$ & ${ }^{\mathrm{a}} 0.496^{\mathrm{ns}}$ \\
\hline $\begin{array}{l}\text { 4th Follow-up ( } 60 \text { days) } \\
\text { Range (min-max) }\end{array}$ & $\begin{array}{l}(n=11) \\
20.91 \pm 7.2 \\
7-33\end{array}$ & $\begin{array}{l}(n=5) \\
19.20 \pm 6.7 \\
13-27\end{array}$ & ${ }^{\mathrm{a}} 0.662^{\mathrm{ns}}$ \\
\hline $\begin{array}{l}\text { 5th Follow-up ( } 90 \text { days) } \\
\text { Range (min-max) }\end{array}$ & $\begin{array}{l}(n=8) \\
14.38 \pm 4.4 \\
7-20\end{array}$ & $\begin{array}{l}(n=5) \\
15.20 \pm 4.0 \\
12-21\end{array}$ & ${ }^{\mathrm{a}} 0.744^{\mathrm{ns}}$ \\
\hline$p$-value & ${ }^{\mathrm{b}} 0.002^{\mathrm{s}}$ & $\mathrm{b}_{0}^{\mathrm{b}} 0.003^{\mathrm{s}}$ & \\
\hline
\end{tabular}

${ }^{a} p$-value reached from unpaired t-test; ${ }^{b} p$-value reached from paired t-test; s, significant; ns, not significant. 
Table 3: Chronological tabulation of survival and mortality of patients with ACLF up to 90 days after commencement of therapy

\begin{tabular}{|c|c|c|c|}
\hline & Surviving & Death & $p$-value \\
\hline \multicolumn{4}{|c|}{ At 7 days after therapy commencement } \\
\hline Group A & 22 & 0 & \\
\hline Group B & 15 & 2 & \\
\hline \multicolumn{4}{|c|}{ At 15 days after therapy commencement } \\
\hline Group A & 15 & 7 & \\
\hline Group B & 13 & 4 & \\
\hline \multicolumn{4}{|c|}{ At 30 days after therapy commencement } \\
\hline Group A & 14 & 8 & 0.509 \\
\hline Group B & 10 & 7 & \\
\hline \multicolumn{4}{|c|}{ At 60 days after therapy commencement } \\
\hline Group A & 11 & 11 & \\
\hline Group B & 5 & 12 & \\
\hline \multicolumn{4}{|c|}{ At 90 days after therapy commencement } \\
\hline Group A & 8 & 14 & 0.457 \\
\hline Group B & 5 & 12 & \\
\hline
\end{tabular}

Table 4: Cause of death of the study population

\begin{tabular}{lcccccr}
\hline & \multicolumn{2}{c}{$\begin{array}{c}\text { Group } A \\
(n=14)\end{array}$} & \multicolumn{2}{c}{$\begin{array}{c}\text { Group } B \\
(n=12)\end{array}$} & \\
\cline { 2 - 5 } Cause of Death & $n$ & $\%$ & $n$ & $\%$ & p-value \\
\hline ACLF with HRS & 5 & 35.7 & 5 & 41.7 & \\
ACLF with HE & 3 & 21.4 & 2 & 16.7 & \\
ACLF with variceal bleeding & 4 & 28.6 & 0 & 0 & $0.332^{\text {ns }}$ \\
ACLF with coagulopathy & 1 & 7.1 & 2 & 16.7 & \\
ACLF with SBP & 1 & 7.1 & 2 & 16.7 & \\
ACLF with septicemia & 0 & 0 & 1 & 8.3 & \\
\hline
\end{tabular}

$\mathrm{ns}$, not significant; $p$-value reached from Chi-square test.

of death in group A, but none in group B. Other causes of death included coagulopathy, spontaneous bacterial peritonitis (SBP), and septicemia (Table 4). In this study, several factors were found to be significantly associated with mortality in univariate analysis including PT, INR, MELD score, and MELDNa score (Table 4).

\section{Discussion}

In the course of the G-CSF and EPO therapy, all patients demonstrated good tolerance. Some patients had minor adverse effects, such as body ache (3 cases) and nausea (3 cases), but all resolved within 3 days and drug discontinuation was not needed. This is consistent with findings of other studies. ${ }^{7,13-15}$

In the present study, CTP score decreased gradually after the G-CSF therapy. Similar findings were seen in other studies. ${ }^{15}$ MELD score also decreased in both groups from pretreatment values, which is consistent with the observation by another study from Bangladesh; ${ }^{14}$ however it was not statistically significant between the two groups. Mean MELDNa score was however not only significantly improved in both groups from baseline but also in group A from group B as was the observation in another study. ${ }^{12}$

In this study, of the total 26 deaths within the 90 -day follow-up, 15 patients $(57.7 \%)$ died within 30 days. This observation is consistent with APASL-ACLF Research Consortium (AARC) data. It appears from the AARC database that over $51.7 \%$ patients with ACLF die by week 4. It is therefore once again emphasized that 4-week (28 days) period should be maintained as per the initial definition for defining the impact of acute event in ACLF.

Several baseline clinical and laboratory variables were analyzed to identify the predictors of mortality. On univariate analysis, PT, INR, MELD score, and MELDNa score were found to be significantly different between the two groups. When these significant variables were entered into multivariate analysis by binary logistic regression, no association was however found to be an independent baseline predictor of mortality. This finding was not supported by other studies that identified $\mathrm{HE}$, esophageal varix, low platelet count, and high serum bilirubin as mortality predictors. ${ }^{14}$

Treatment with G-CSF and EPO yielded better survival at 90 days $(36.4 \%$ in group A vs $29.4 \%$ in group B) and lower rate of HRS ( $35.7 \%$ vs $41.7 \%$ in groups $A$ and $B$, respectively), but not statistically significant. Survival benefit in ACLF was possibly due to an increase in neutrophil count, which also contributed to fewer HRS. Neutrophil dysfunction has been shown to cause sepsis and further the development of HRS in patients with ACLF. ${ }^{16}$

\section{Conclusion}

The study demonstrated the safety of combination therapy of G-CSF with EPO in ACLF. Some survival benefit was also seen. This is the first human study using G-CSF and EPO in ACLF where potential hepatic regeneration has been documented. The results of the present study would need to be confirmed in a larger cohort of patients with ACLF.

\section{References}

1. Sarin SK, Kumar A, Almeida JA, et al. Acute-on-chronic liver failure: consensus recommendations of the Asian Pacific Association for the study of the liver (APASL); Hepatol Int 2009;3(1):269-282. DOI: 10.1007/ s12072-008-9106-x.

2. Sarin S, Chandan K, Zaigham A, for APASL ACLF working partly, et al. Acute-on-chronic liver failure: consensus recommendations of the Asian Pacific Association for the study of the liver (APASL) 2014. Hepatol Int 2014;8(4):453-471. This is the consensus statement of APASL on ACLF. It provides the definition, concept and management of ACLF patients. DOI: 10.1007/s12072-014-9580-2.

3. Kjaergard LL, Liu J, Als-Nielsen B, et al. Artificial and bioartificial support systems for acute and acute-on-chronic liver failure: a systematic review. JAMA 2003;289(2):217-222. DOI: 10.1001/ jama.289.2.217.

4. Sarin SK, Kumar A, Garg HK. Clinical profile of acute on chronic liver failure (ACLF) and predictors of mortality: a study of 64 patients. Hepatology 2008;48(Suppl):450A.

5. Grove JE, Bruscia E, Krause DS. Plasticity of bone marrow-derived stem cells. Stem Cells 2004;22(4):487-500. DOI: 10.1634/stemcells.22-4-487.

6. Fogt F, Beyser KH, Poremba C, et al. Recipient-derived hepatocytes in liver transplants: a rare event in sex-mismatched transplants. Hepatology 2002;36(1):173-176. DOI: 10.1053/jhep.2002.33994.

7. Garg V, Garg H, Khan A, et al. Granulocyte colony-stimulating factor mobilizes CD34(+) cells and improves survival of patients with acuteon-chronic liver failure. Gastroenterology 2012;142(3):505-512.e1. DOI: 10.1053/j.gastro.2011.11.027.

8. Spahr L, Lambert JF, Brandt LR, et al. Granulocyte-colony stimulating factor induces proliferation of hepatic progenitors in alcoholic steatohepatitis: a randomized trial. Hepatology 2008;48(1):221-229. DOI: 10.1002/hep.22317.

9. Mookerjee RP, Stadlbauer V, Lidder S, et al. Neutrophil dysfunction in alcoholic hepatitis superimposed on cirrhosis is reversible and predicts the outcome. Hepatology 2007;46(3):831-840. DOI: 10.1002/ hep.21737. 
10. Visser G, Rake JP, Labrune P, et al. Granulocyte colony-stimulating factor in glycogen storage disease type 1b. Results of the European Study on Glycogen Storage Disease Type 1. Eur J Pediatr 2002;161(Suppl 1):S83-S87. DOI: 10.1007/s00431-002-1010-0.

11. Ben Ari Z, Zilbermints V, Pappo O, et al. Erythropoietin increases survival and attenuates fulminant hepatic failure induced by D-galactosamine/lipopolysaccharide in mice. Transplantation 2011;92(1):18-24. DOI: 10.1097/TP.0b013e31821cdea5.

12. Kedarisetty CK, Anand L, Bhatia V, et al. Combination of granulocyte colony-stimulating factor and erythropoietin improves outcomes of patients with decompensated cirrhosis. Gastroenterology 2015;148(7):1362-1370.e7. DOI: 10.1053/j.gastro.2015.02.054.

13. Mahtab MA, Alam SMN, Moben AL, et al. Therapy targeting stem cell in patients with decompensated cirrhosis of liver in a tertiary treatment care center of Bangladesh. Euroasian J Hepatogastroenterol 2017 Jan-Jun;7(1):113-115. DOI: 10.5005/jp-joumals-10018-1229.

14. Saha BK, Mahtab MA, Akbar SMF, et al. Therapeutic implications of granulocyte colony stimulating factor in patients with acute-onchronic liver failure: increased survival and containment of liver damage. Hepatol Int 2017;11(6):540-546. DOI 10.1007/s12072-0179814-1.

15. Duan XZ, Liu FF, Tong JJ, et al. Granulocyte-colony stimulating factor therapy improves survival in patients with hepatitis $B$ virusassociated acute on- chronic liver failure. World J Gastroenterol 2013;19(7):1104-1110. DOI: 10.3748/wjg.v19.i7.1104.

16. Leber B, Spindelboeck W, Stadlbauer V. Infectious complications of acute and chronic liver disease. Semin Respir Crit Care Med 2012;33(1):80-95. DOI: 10.1055/s-0032-1301737. 